\title{
Analysis of the Method of Heating and Cooling of an Office Building ${ }^{\dagger}$
}

\author{
Monika Pogorzelska * and Dorota Anna Krawczyk \\ Faculty of Civil and Environmental Engineering, Bialystok University of Technology, 45A, Wiejska Street, \\ 15-351 Bialystok, Poland; d.krawczyk@pb.edu.pl \\ * Correspondence: mp.pogorzelska@gmail.com; Tel.: +48-794-145-055 \\ + Presented at the 9th Innovations-Sustainability-Modernity-Openness Conference (ISMO'20), Bialystok, \\ Poland, 20-21 May 2020.
}

Published: 19 November 2020

\begin{abstract}
The aim of this paper was the analysis of the heating and cooling of a two-story office building located in northeastern Poland, which leads to making practical conclusions. The main part of the work focuses on determining the projected heat loss as well as heat profits of the building under scrutiny, in which the information serves as initial data for the selection of devices of the systems under analysis. For the analysis, we assess the installation of fan coils-underfloor - which heat or cool a room and the installation of radiators for heat, and the multi-split air conditioner for cooling. For every variant, we estimated the investment costs and the operating costs. The comparison enabled to present conclusions and advice concerning the heating and cooling of small office buildings. In the summary, the reader will be able to familiarize with conclusions concerning the price and comfort of the implementation of solutions.
\end{abstract}

Keywords: thermal comfort; fan coils; heating; cooling; office buildings

\section{Introduction}

Ensuring a proper air quality and thermal comfort are key functions of heating and cooling systems in buildings. Modern office buildings are designed for planning efficient installations; however, they require to be energy-saving and aesthetic. They affect the ever-growing expectations of users regarding a favorable microclimate in the operation of work. This is associated with increased productivity of employees staying many hours in the general office space. Achieving a satisfied level of users can be made by several solutions that meet the conditions and technical requirements [1-3].

The room microclimate depends on the air speed, humidity and air temperature. This is the most important term for thermal comfort in which a person functions best. Thermal comfort is determined by the state of thermal equilibrium of the body connection, the lack of discomfort due to the feeling of heat or cold - the temperature is felt within a range. The appropriate exchange of air and humidity has an additional impact on human well-being. Moreover, it should be remembered that the feeling of thermal comfort is perceived individually by each person [4-6].

The selection of an appropriate method of heating should take in account climatic, investment conditions and individual needs.

\section{Methodology}

Two variants of heating and cooling systems in the office building were analyzed. The first variant of space heating and cooling was fan coils. This system operates in a four-pipe system for heating and cooling simultaneously. The heating and cooling medium distribution pipes are distributed in the floor. The heating system's operating parameters are assumed to be equal: $40 / 30^{\circ} \mathrm{C}$, 
and the cooling system at $7 / 14{ }^{\circ} \mathrm{C}$, and is a system powered by an air heat pump which was selected based on the calculation results.

The second variant included convector heaters, which were designed for full functionality in low-temperature heating systems, as well as for built-in fans with control, providing a higher heat output than standard solutions. The regulation of installations with convector heaters is done by means of valves on the supply and return side. The heating medium distribution pipes are laid in the floor. An air heat pump was used as the heat source. The heating system's operating parameters are assumed to be equal: $40 / 30^{\circ} \mathrm{C}$, and the cooling system: $7 / 14^{\circ} \mathrm{C}$.

Multi-split air conditioning was used for cooling. In the office rooms located on the ground and first floor, three indoor units with heating, cooling and dehumidifying functions and a fan were selected. The refrigerant supply pipes were distributed in the suspended ceiling space. The operation of air conditioners can be controlled by means of a wireless controller. Air conditioners are operated by means of external units - mounted on the building roof. The units are equipped with a metal cover with a coating to protect against external factors. The refrigerant used for air conditioning is R-32.

The design of fan coils and radiator systems was made using the Instalsoft HCR and Instalsoft OZC programs. Based on the results of the calculations of the heat gains of the analyzed building, multi-split air conditioning was chosen, which was selected using the Samsung catalog card.

The analysis was made in order to compare the ways of heating an office building. The comparison of operating costs and investment outlays allowed to separate a cheaper way of heating and cooling, which will make the investor's choice easier.

\section{Results}

Two variants of heating and cooling were analyzed. The first one is an installation with fan coils-for heating and cooling-and the second one is convector heaters and multi-split air conditioning. The results showed higher capital expenditure on the installation with fan coils. Compared with the cost of an installation with convector heaters, this increase was by $20 \%$, so it is a more expensive investment, but not significantly. We must remember that in both cases, the focus was on aesthetics and thermal comfort.

In the next step, the investment outlays of the individual variants for the lower heat source were taken into account. The analysis also included operating costs, i.e., the price which an investor has to pay when using electricity, which was made in the Aquarea Designer program. The cost of execution in the case of installations with fan coils was lower than the variant with convector heaters and multisplit air conditioning by $8 \%$. This is due to the use of a heat pump for heating and for cooling the medium in air conditioning which was more expensive by $41 \%$.

The general costs are presented in Figure 1. According to [7], the average price of equipment was based on catalogs. Costs that investors will have to bear for fan coils are $1 \%$ higher than radiators with air conditioning.

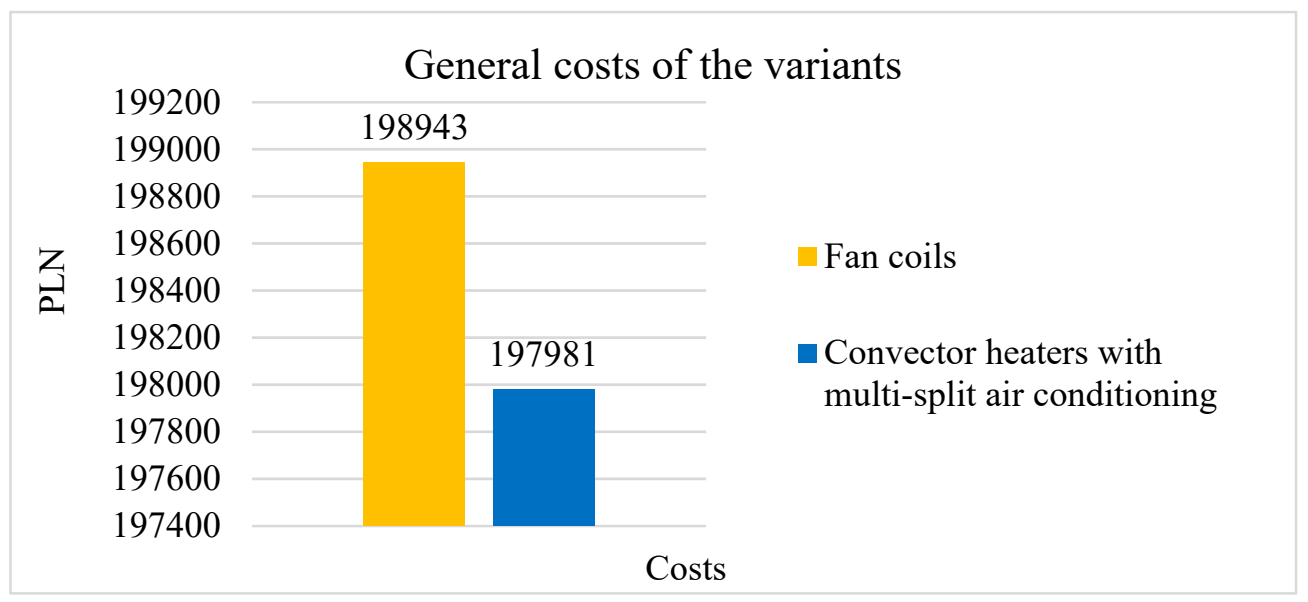

Figure 1. General costs of the variants [7]. 


\section{Conclusions}

Looking at the total investment outlay in the analyzed methods of heating and cooling, we can choose a variant with convector heaters and multi-split air conditioning.

It is important to pay attention to the much lower operating costs of a heat pump with a higher power, which supplies the medium for duct fan coils and the aesthetics of the installation. This variant does not require the installation of additional cooling devices, as the convector itself is used for heating and cooling.

We must remember that the comparison concerns maintenance-free heat sources, which does not require taking into account the operating costs, but it is necessary to pay attention to the need for service inspections and maintenance of the equipment in both variants. These prices on the market are very similar to each other.

Author Contributions: D.A.K. conceived and designed the experiments; M.P. performer the experiments, analyzed the data and wrote the paper. All authors have read and agreed to the published version of the manuscript.

Conflicts of Interest: The authors declare no conflict of interest.

\section{References}

1. Cen, C.; Jia, Y.; Liu, Y.; Geng, R. Experimental comparison of thermal comfort during cooling with a fan coil system and radiant floor system at varying space heights. Build. Environ. 2018, 141, 71-79, doi:10.1016/j.buildenv.2018.05.057.

2. Márquez, A.A.; López, J.M.; Hernández, F.; Muñoz, F.; Andrés, A. A comparison of heating terminal units: Fan-coil versus radiant floor, and the combination of both. Build. Environ. 2017, 138, 621-629, doi:10.1016/j.enbuild.2016.12.092.

3. Hundy, G.F.; Trott, A.R.; Wlech, C. Chapter 24-Air Conditioning Methods and Applications. In Refrigeration, Air Conditioning and Heat Pumps, 5th ed.; Butterworth-Heinemann: Oxford, UK, 2016; pp. 375392, doi:10.1016/B978-0-08-100647-4.00024-3.

4. Rhee, K.-N.; Kim, K.W. A 50 year review of basic and applied research in radiant heating and cooling systems for the built environment. Build. Environ. 2015, 91, 166-190, doi:10.1016/j.buildenv.2015.03.040.

5. Krawczyk, D.A.; Wądołowska, B.; Rodero, A. Comparison of cooling load and air conditioning systems in a lecture hall located in Poland and Spain. In Proceedings of the 10th Conference on Interdisciplinary Problems in Environmental Protection and Engineering EKO-DOK, Polanica-Zdrój, Polska, 16-18 April 2018. doi:10.1051/e3sconf/20184400081.

6. Witkowska, A.; Krawczyk, D.A.; Rodero, A. Investment Costs of Heating in Poland and Spain-A Case Study. Proceedings 2019, 16, 40, doi:10.3390/proceedings2019016040.

7. Pogorzelska, M. Analysis of the Method of Heating and Cooling of an Office Building. Master's Thesis, Bialystok University of Technology, Białystok, Poland, 2019.

Publisher's Note: MDPI stays neutral with regard to jurisdictional claims in published maps and institutional affiliations.

(C) 2020 by the authors. Licensee MDPI, Basel, Switzerland. This article is an open access article distributed under the terms and conditions of the Creative Commons Attribution (CC BY) license (http://creativecommons.org/licenses/by/4.0/). 